\title{
Alloisoleucine Formation in Maple Syrup Urine Disease: Isotopic Evidence for the Mechanism
}

\author{
D. E. MATTHEWS, ${ }^{\{15\}}$ E. BEN-GALIM, M. W. HAYMOND, AND D. M. BIER \\ Departments of Medicine and Pediatrics, Washington University School of Medicine, St. Louis, Missouri, USA
}

\begin{abstract}
Summary
Of the four possible stereoisomers of isoleucine, only L-alloisoleucine and L-isoleucine were found by capillary gas chromatography in the plasma of two maple syrup urine disease (MSUD) patients, one with classical and one with variant MSUD. The relative plasma concentration ratios of $\mathrm{L}$-alloisoleucine/L-isoleucine were $0.795 \pm 0.025( \pm 95 \%$ confidence limits $)$ and $0.637 \pm$ 0.016 in the classical- and variant-MSUD patients, respectively. The patients were also studied in the postabsorptive state with a 6-hr continuous infusion of $\mathrm{L}-\left[{ }^{15} \mathrm{~N} \mid\right.$ leucine. In each patient plasma leucine ${ }^{15} \mathrm{~N}$ enrichment approximated plateau after $150 \mathrm{~min}$, and there was rapid appearance of $\left[{ }^{15} \mathrm{~N}\right]$ isoleucine and $\left[{ }^{15} \mathrm{~N}\right]$ alloisoleucine which were identical at plateau, although in the variantMSUD patient $\left[{ }^{15} \mathrm{~N} \mid\right.$ alloisoleucine enrichment did not equal that of $\left[{ }^{15} \mathrm{~N}\right.$ )isoleucine until $240 \mathrm{~min}$ of infusion. These results offer direct in vivo evidence for the rapid equilibrium of plasma isoleucine and alloisoleucine through keto-enol tautomerization of $\alpha$ keto- $\beta$-methylvalerate.
\end{abstract}

\section{Speculation}

Infusion of a ${ }^{15} \mathrm{~N}$-labeled, branched-chain amino acid with measurement of ${ }^{15} \mathrm{~N}$ incorporation into the other branched-chain amino acids may provide useful information about branched-chain amino acid metabolism and offer a new approach to estimating in vivo branched-chain amino acid transferase activity.

Although all protein amino acids, except glycerine, have a chiral $\alpha$-carbon center, only isoleucine and threonine have a chiral $\beta$ carbon center as well. Mammalian protein synthesis is specific for amino acids with the proper orientation not only about the $\alpha$ carbon, but also about the $\beta$-carbon where this option applies. Of the four possible stereoisomers of isoleucine, L- and D-isoleucine and $\mathrm{L}$ and $\mathrm{D}$-alloisoleucine, the only stereoisomer normally present in blood is L-isoleucine. However, when the L-isoleucine plasma concentration is greatly elevated as in maple syrup urine disease (MSUD), L-alloisoleucine is also found (12). This amino acid, originally mistaken for methionine because the two amino acids eluted together on the ion-exchange columns of earlier workers (14), was first positively identified as alloisoleucine by Norten et al. (11). Two years later, the same group presented indirect evidence that only L-alloisoleucine and not D-alloisoleucine was present in MSUD plasma (12) and postulated that L-alloisoleucine was formed endogenously by the mechanism outlined in Figure 1. Under normal metabolic conditions, $(+)$ - $\alpha$-keto- $\beta$-methylvaleric acid (KMV), is oxidatively decarboxylated and does not accumulate in the plasma (3). In MSUD, the decarboxylation step is blocked, and plasma and tissue concentrations of KMV are greatly elevated. Under these conditions, it was proposed (12) that enolization of (+)-KMV produces (-)-KMV which is subsequently reaminated to form $\mathrm{L}$-alloisoleucine.

In 1970, Halpern and Pollock, using capillary gas chromatography, showed that L-alloisoleucine and not the D-form was present in the plasma of an MSUD patient (5). In 1977, Jakobs et al. (7), also using capillary gas chromatography, identified nearly equal amounts of $(+)$ - and (-)-KMV in the three MSUD patients studied. The above workers provided theoretical evidence for the endogenous formation of $\mathrm{L}$-alloisoleucine in MSUD, but direct in vivo verification of the mechanism outlined in Figure 1 was still speculative. In this work, we have infused two MSUD patients with L- $\left[{ }^{15} \mathrm{~N}\right]$ leucine and have measured the subsequent incorporation of ${ }^{15} \mathrm{~N}$ into plasma isoleucine and alloisoleucine. The results provide strong supporting evidence that, indeed, L-alloisoleucine formation in MSUD occurs via the keto-enol tautomerization of KMV,

\section{MATERIALS AND METHODS}

PATIENTS AND STUDY PROTOCOL

Two MSUD patients were studied: a $65 / 12$-yr-old Caucasian girl with classical MSUD (C-MSUD) discovered on the third day of life, and a $2 \% 112$-year-old Negro girl with variant MSUD (VMSUD) diagnosed at the age of 14 months. Both patients were maintained on diets sufficiently depleted in the branched-chain amino acids to keep isoleucine and valine plasma concentrations near normal and leucine concentrations below 1.4 and $0.7 \mathrm{mM}$ for the C-MSUD and V-MSUD patients, respectively. These patients have been described completely elsewhere as subjects 2 and 4 of a previous report (6).

Both patients were studied at Washington University Pediatric Clinical Research Center after written parental consent was obtained. Each subject was studied in the postabsorptive state after a 14-hr overnight fast. On the morning of study, a "scalp vein" needle was inserted into an antecubital vein for administration of a 15.0 and $7.5 \mu$ moles $/ \mathrm{kg} \mathrm{L}-\left[{ }^{15} \mathrm{~N}\right]$ leucine priming dose in the CMSUD and V-MSUD patient, respectively, followed immediately by a continuous infusion of $\mathrm{L}-\left[{ }^{15} \mathrm{~N}\right]$ leucine at the rate of $15 \mu$ moles/ $\mathrm{kg} / \mathrm{hr}$ for $6 \mathrm{hr}$ in each subject. A contralateral scalp vein needle was inserted for withdrawing 3-ml blood samples prior to administration of the priming dose and at appropriate intervals thereafter for $6 \mathrm{hr}$. Each specimen was immediately placed on ice and promptly centrifuged to remove the plasma which was stored at $-70^{\circ} \mathrm{C}$ until analysis.

\section{PREPARATION OF MATERIALS FOR HUMAN USE}

L- $\left[{ }^{15} \mathrm{~N}\right]$ Leucine $\left(95 \%{ }^{15} \mathrm{~N}\right)$ was purchased from Merck, Sharp and Dohme, Ltd. (Pointe Duval, Quebec, Canada) and tested for chemical purity, isotopic purity, and pyrogenicity. $\mathrm{L}-\left[{ }^{15} \mathrm{~N}\right]$ Leucine was dissolved in sterile, pyrogen-free, $0.45 \% \mathrm{NaCl}$ solution with aseptic technique. The solution was then passed through a sterile $0.22-\mu \mathrm{m}$ Millipore filter into sterile vials that were subsequently sealed with rubber stoppers and crimped metal caps. Aliquots were removed aseptically as needed.

\section{SAMPLE PREPARATION}

From $250 \mu \mathrm{l}$ aliquots of plasma, the free amino acids were isolated by ion-exchange chromatography as previously described 

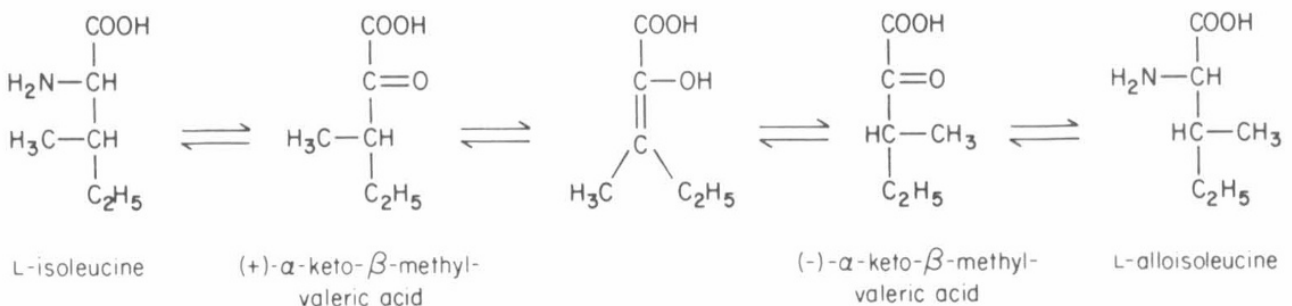

$(-)-\alpha$-keto- $\beta$-methyl-
valeric acid

L-alloisoleucine

Fig. 1. Proposed mechanism of formation of L-alloisoleucine in MSUD by enolization of KMV.

$(1,2)$. From each set of aliquots, different amino acid derivatives were prepared: (1) the $N$-pentafluoropropionyl $n$-propyl (PFP) esters $(1,4)$ for separation of stereoisomers by capillary gas chromatography; (2) the trimethylsilyl (TMS) esters (2) for determination of ${ }^{15} \mathrm{~N}$ enrichment in plasma leucine; and (3) the $N$ acetyl $n$-propyl (NAP) esters $(1,9)$ for measurement of ${ }^{15} \mathrm{~N}$ content of plasma isoleucine and alloisoleucine.

\section{CAPILLARY GAS CHROMATOGRAPHY}

The four isoleucine stereoisomers as the PFP derivatives were separated with a $25-\mathrm{m} \times 0.3-\mathrm{mm}$ ID Chirasil-Val glass capillary column (Applied Science Labs, State College, PA) mounted in a Varian model 3700 gas chromatograph equipped for capillary columns with a splitter injector and flame ionization detector. The peak retention times and peak areas were recorded with a SpectraPhysics System I computing integrator (Santa Clara, CA). The Varian 3700 was operated with an injector splitter ratio of 100:1 and a helium carrier gas flow of $1 \mathrm{ml} / \mathrm{min}$, and both injector and detector were kept at $200^{\circ} \mathrm{C}$. The capillary column was held at $100^{\circ} \mathrm{C}$ for $2 \mathrm{~min}$ after sample injection before increasing the temperature at $2^{\circ} \mathrm{C} / \mathrm{min}$.

\section{ISOTOPIC MEASUREMENTS}

${ }^{15} \mathrm{~N}$ enrichments in plasma branched-chain amino acids were determined by computer-controlled, selected-ion-monitoring gas chromatography-mass spectrometry using a Finnigan 3200 quadrupole instrument operated in the electron impact mode (9).

Gas chromatographic separation of TMS-leucine was effected with a $2-\mathrm{m} \times 2-\mathrm{mm}$ ID glass column packed with $10 \% \mathrm{OV}-11$. Using a helium flow rate of $30 \mathrm{ml} / \mathrm{min}$, the column temperature was programmed at a rate of $4^{\circ} \mathrm{C} / \mathrm{min}$ after sample injection at $150^{\circ} \mathrm{C}$. ${ }^{15} \mathrm{~N}$ enrichment in TMS-leucine was determined by monitoring nominal masses 158 and 159 , the $\left[\mathrm{M}\right.$-COOTMS ${ }^{+}$fragment ion and its ${ }^{15} \mathrm{~N}$-labeled counterpart. Gas chromatographic separation of NAP-alloisoleucine, NAP-isoleucine, and NAP-leucine was effected using a $1-\mathrm{m} \times 2-\mathrm{mm}$ ID glass column packed with a mixed phase $(0.3 \%$ Carbowax $20 \mathrm{M}, 0.3 \%$ Silar $5 \mathrm{CP}$, and $0.05 \%$ Lexan) on Chromosorb W AW 120-140 mesh obtained from J. Graff Associates (Santa Clara, CA). Using a helium flow rate of $18 \mathrm{ml} / \mathrm{min}$, the temperature was programmed at $4^{\circ} \mathrm{C} / \mathrm{min}$ after sample injection at $100^{\circ} \mathrm{C}$. ${ }^{15} \mathrm{~N}$ enrichments in $\mathrm{NAP}$-isoleucine and NAP-alloisoleucine were measured by monitoring nominal masses 128 and 129 , the $\left[\mathrm{M}-\mathrm{COOC}_{3} \mathrm{H}_{7}\right]^{+}$fragment ion cluster (9). For both the TMS and NAP derivatives, the gas chromatography column was stepped to $250^{\circ} \mathrm{C}$ after leucine had eluted to remove rapidly the other amino acids from the column.

\section{RESULTS}

\section{IDENTIFICATION OF ISOLEUCINE STEREOISOMERS IN THE MSUD} PATIENT PLASMA

Figure 2 shows the gas chromatographic resolution of plasma branched-chain amino acids as their NAP derivatives. This separation, intended primarily for computing ${ }^{15} \mathrm{~N}$ enrichments in alloisoleucine and isoleucine (to be discussed shortly), can also be used to measure the relative concentration of alloisoleucine and isoleucine. Under the packed conditions described, alloisoleucine,

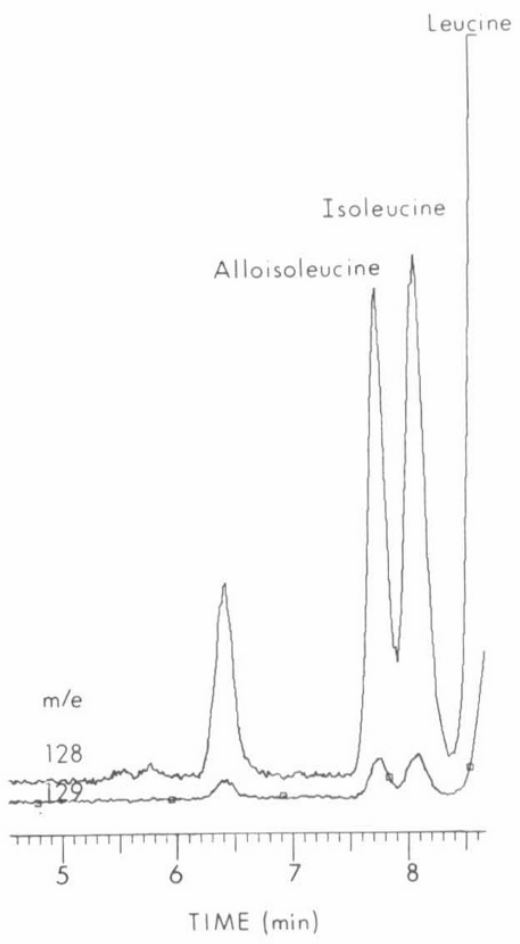

Fig. 2. Gas chromatography-mass spectrometry, selected-ion chromatogram of alloisoleucine, isoleucine, and leucine from a MSUD patient plasma sample. The branched-chain amino acids were chromatographed as the NAP derivatives, and masses 128 and 129 were monitored. Leucine, present in the MSUD plasma in large concentration, was plotted off scale in this figure to magnify the alloisoleucine and isoleucine peaks and illustrate their chromatographic resolution.

isoleucine, and leucine are resolved but their D- and L-forms coelute.

The small overlap between the alloisoleucine and isoleucine peaks shown in Figure 2 is of little consequence for quantitative measurements if peak height rather than area measurements is used. Assuming that the gas chromatography peaks follow a Gaussian distribution (i.e., tailing is minor), the overlap of the side of either peak can be calculated and, under the conditions used here, is less than $6 \%$. The average plasma alloisoleucine:isoleucine concentration ratio in the present study was $0.795 \pm 0.025$ (mean $\pm 95 \%$ confidence limits) in the C-MSUD patient and $0.637 \pm$ 0.016 in the V-MSUD subject. Thus, of the total isoleucine stereoisomers, alloisoleucine comprised $44.3 \pm 2.0 \%$ in the CMSUD patient and $38.9 \pm 1.3 \%$ in the V-MSUD patient.

High-resolution capillary gas chromatography of the PFPamino acid derivatives was used to determine the amount of each D- and L-branched-chain amino acid stereoisomer. Figure $3 d$ is a capillary gas chromatogram of a standard mixture of the four isoleucine stereoisomers in the presence of other L-amino acids. As shown, the D- and L-alloisoleucine (peaks 4b and 5a) and Dand $\mathrm{L}$ - isoleucine (peaks $5 \mathrm{~b}$ and 6 ) pairs are well resolved; $\mathrm{L}-$ alloisoleucine (peak 5a) and D-isoleucine (peak 5b) are separated sufficiently to detect a small amount of one in the presence of the other. [Although glycine (peak 4a) and D-alloisoleucine (peak 4b) 
elute almost concurrently, this overlap will be shown to be unimportant].

Neither L-alloisoleucine or D-isoleucine was detected in the plasma from a normal person (Fig. $3 c$ ). On the other hand, Lalloisoleucine was found in both the V-MSUD and C-MSUD patients (Fig. 3, $a$ and $b$ ). The plasma L-alloisoleucine:L-isoleucine ratios calculated for the C-MSUD and V-MSUD patients were 0.786 and 0.637 , values identical with those measured by packedcolumn gas chromatography. Inasmuch as no D-isoleucine was found in either plasma and because the DL-alloisoleucine:DL-isoleucine ratio from packed column chromatography was equivalent to the capillary column L-alloisoleucine:L-isoleucine ratio, no D-alloisoleucine is present under the glycine peaks in Figure 3, $a$ and $b$.

\section{${ }^{15} \mathrm{~N}$ ENRICHMENT IN PLASMA LEUCINE}

Table 1 shows the ${ }^{15} \mathrm{~N}$ enrichment in plasma leucine during the 6-hr continuous infusion of $\mathrm{L}-\left[{ }^{15} \mathrm{~N}\right]$ leucine in each subject. Plasma $\left[{ }^{15} \mathrm{~N}\right]$ leucine approximated plateau after $150 \mathrm{~min}$ in each case. For the C-MSUD and V-MSUD patients, plasma atom percentage of excess ${ }^{15} \mathrm{~N}$ at plateau was equal to $1.86 \pm 0.07$ and $2.55 \pm 0.12$ (mean $\pm 95 \%$ confidence limits), respectively.

\section{${ }^{15} \mathrm{~N}$ ENRICHMENT IN PLASMA ISOLEUCINE AND ALLOISOLEUCINE}

Table 2 shows that ${ }^{15} \mathrm{~N}$ from leucine rapidly appeared in plasma isoleucine and alloisoleucine in both MSUD patients. In the C-

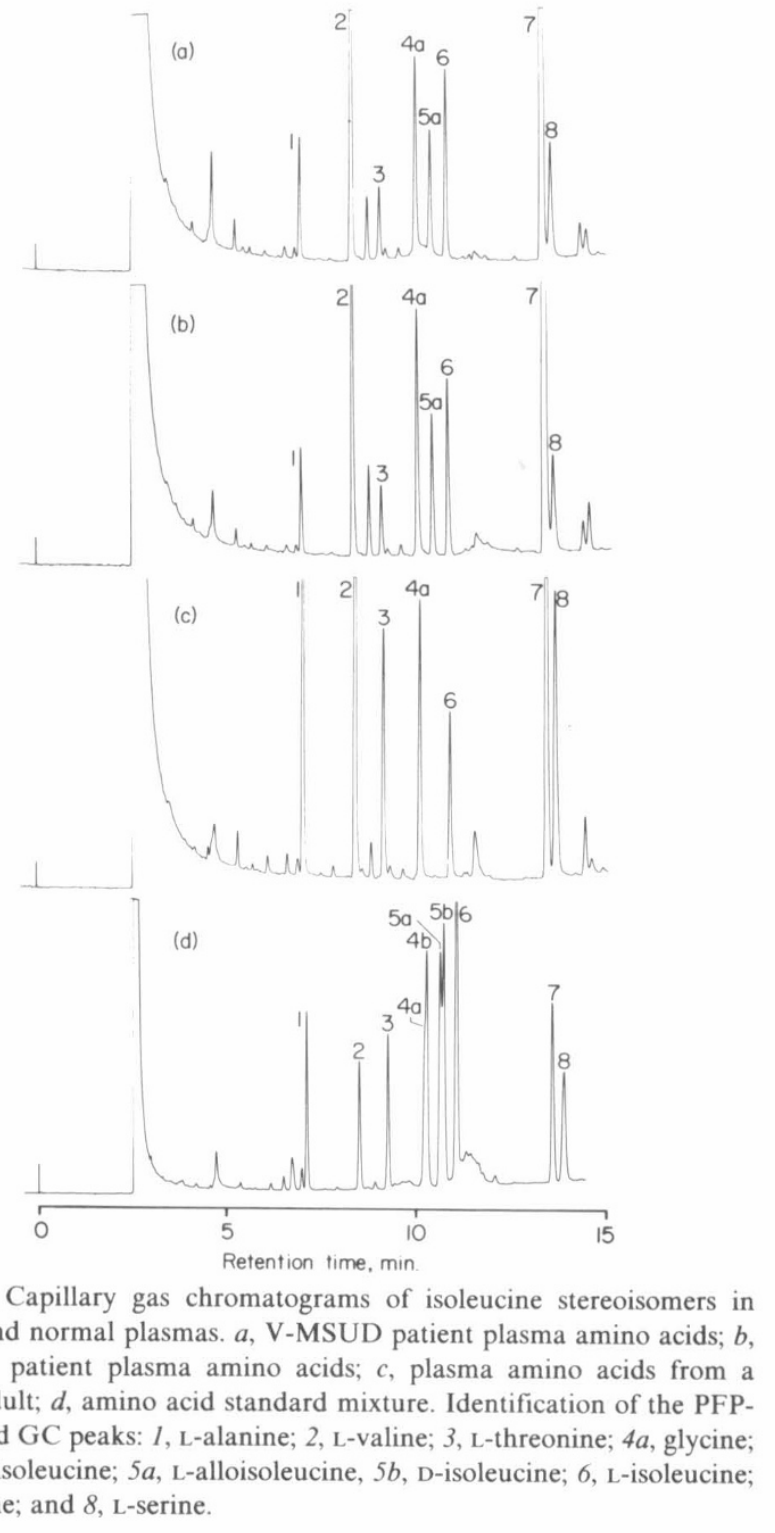

Table 1. Plasma leucine ${ }^{15} \mathrm{~N}$ enrichment during a primed, continuous infusion of $L-\left[{ }^{15} N\right]$ leucine into two MSUD patients

\begin{tabular}{ccc}
\hline & \multicolumn{2}{c}{ Plasma leucine atom \% excess } \\
Time after start of infusion & \multicolumn{2}{c}{${ }^{15} \mathrm{~N}$} \\
\cline { 2 - 3 }$(\min )$ & C-MSUD & V-MSUD \\
& patient & patient \\
\hline 0 & 0 & 0 \\
60 & 1.34 & 2.00 \\
120 & 1.63 & 2.10 \\
150 & 1 & 2.39 \\
180 & 1.73 & 2.35 \\
210 & 1.77 & 2.42 \\
240 & 1.81 & 2.42 \\
270 & 1.87 & 2.65 \\
300 & 1.85 & 2.78 \\
315 & 1.86 & 2.75 \\
335 & 1.95 & 2.55 \\
345 & 1.99 & 2.60 \\
& & $2.55 \pm 0.12$ \\
\hline confidence limits ${ }^{2}$ & $1.86 \pm 0.07$ & \\
\hline
\end{tabular}

${ }^{1}$ Blood sample at $150 \mathrm{~min}$ not obtained.

${ }^{2}$ Mean of values from $150 \mathrm{~min}$ and later.

Table 2. Plasma $\left[{ }^{15} \mathrm{~N}\right]$ isoleucine and $\left[{ }^{15} \mathrm{~N}\right]$ alloisoleucine in two $M S U D$ patients during continuous infusion of $L-\left[{ }^{15} N\right]$ leucine

\begin{tabular}{ccc}
\hline Time after start & \multicolumn{2}{c}{ Atom \% excess ${ }^{15} \mathrm{~N}$} \\
\cline { 2 - 3 } $\begin{array}{c}\text { of infusion } \\
(\min )\end{array}$ & Isoleucine & Alloisoleucine \\
\hline
\end{tabular}

\section{C-MSUD patient ${ }^{1}$}

\begin{tabular}{rll}
0 & \multicolumn{1}{c}{0} & 0 \\
60 & $1.00 \pm 0.07^{2}$ & $0.85 \pm 0.08$ \\
120 & 1.22 & 1.14 \\
180 & 1.38 & 1.42 \\
240 & 1.38 & 1.31 \\
270 & 1.42 & 1.34 \\
360 & 1.52 & 1.53
\end{tabular}

V-MSUD patient

$\begin{array}{rcc}0 & 0 & 0 \\ 60 & 0.93 \pm 0.06 & 0.65 \pm 0.09^{3} \\ 120 & 1.19 \pm 0.02 & 0.81 \pm 0.05^{4} \\ 180 & 1.19 \pm 0.05 & 0.88 \pm 0.04^{4} \\ 210 & 1.26 \pm 0.02 & 1.00 \pm 0.05^{4} \\ 240 & 1.39 \pm 0.04 & 1.24 \pm 0.11 \\ 270 & 1.33 \pm 0.04 & 1.37 \pm 0.06 \\ 335 & 1.37 \pm 0.06 & 1.39 \pm 0.05\end{array}$

${ }^{1}$ S.E. values for all time points similar to the 60 -min values.

${ }^{2}$ Mean \pm S.E.

${ }^{3} P<0.05$ significant difference between corresponding isoleucine and alloisoleucine ${ }^{15} \mathrm{~N}$ enrichments.

${ }^{4} P<0.01$ significant difference between corresponding isoleucine and alloisoleucine ${ }^{15} \mathrm{~N}$ enrichments.

MSUD patient, $\left[{ }^{15} \mathrm{~N}\right]$ isoleucine and $\left[{ }^{15} \mathrm{~N}\right]$ alloisoleucine enrichments were identical at every time point and approached a plateau coincident with plasma $\left[{ }^{15} \mathrm{~N}\right]$ leucine enrichment (Table 1). In contrast, in the V-MSUD patient, $\left[{ }^{15} \mathrm{~N}\right]$ alloisoleucine enrichment rose more slowly and did not approximate that of $\left[{ }^{15} \mathrm{~N}\right]$ isoleucine until $240 \mathrm{~min}$.

\section{DISCUSSION}

Although the mechanism (Fig. 1) proposed in 1964 by Snyderman et al. (12) for the formation of alloisoleucine in MSUD has become generally accepted, there is no direct in vivo evidence that this hypothesis is, in fact, correct. One line of supporting evidence is the finding of only the L-form of alloisoleucine in the plasma of 
an MSUD patient by Halpern and Pollack (5); however, this report represented the study of a single MSUD patient, and the generality of the observation has, to our knowledge, not been independently confirmed in other MSUD subjects until the present report. Inasmuch as branched-chain amino acid transferase (EC 2.6.1.6) is specific for L-branched-chain amino acids (13), the occurrence of only L-alloisoleucine in MSUD plasma provided indirect evidence for the mechanism outlined. It is possible, however, that any D-alloisoleucine formed is either rapidly metabolized or readily cleared. Because almost all of a small D-alloisoleucine dose given an MSUD patient was recovered in the urine (12), only the latter alternative is plausible. Our chromatography techniques discussed above can detect as little as $2 \%$ of the total alloisoleucine as the D-isomer in the MSUD plasmas. To keep the D-alloisoleucine plasma concentration below this figure, renal clearance of the D-isomer must be at least 50 times greater than the L-isomer. Because Snyderman et al. (12) have shown that Dalloisoleucine is cleared only about five times faster than the Lisomer, the absence of measurable D-alloisoleucine in the MSUD patient is not due to rapid renal clearance.

Jakobs et al. (7) have provided further supporting evidence for the enolization hypothesis by showing near equal concentrations of (+)- and (-)- KMV in the blood of one and the urine of three MSUD patients.

If enolization of $\mathrm{KMV}$ is active, the alloisoleucine and isoleucine pools will be directly connected. During an infusion of $\mathrm{L}-\left[{ }^{15} \mathrm{~N}\right]$ leucine into MSUD patients, the ${ }^{15} \mathrm{~N}$ enrichments would be expected to increase in alloisoleucine and isoleucine until isotopic steady state is reached, at which point the levels of ${ }^{15} \mathrm{~N}$ enrichments would be identical. The data presented in Table 2 show that the ${ }^{15} \mathrm{~N}$ enrichments in the two amino acids are indistinguishable after $60 \mathrm{~min}$ for the C-MSUD patient and after $240 \mathrm{~min}$ in the VMSUD patient. If the enolization mechanism racemizing (+)- and $(-)-\mathrm{KMV}$ were not active, ${ }^{15} \mathrm{~N}$ could still be incorporated into the alloisoleucine and isoleucine pools of the MSUD patients via branched-chain amino acid transferase. However, the levels of ${ }^{15} \mathrm{~N}$ enrichment in alloisoleucine and isoleucine would only be equal if the turnover rates of the two amino acids were the same. This is extremely unlikely because isoleucine kinetics would include incorporation into and release from body protein whereas these substantial rate constants would be absent from the considerations of plasma alloisoleucine disposition.

Alternatively, it might be suggested that the transamination step is much faster than the enolization reaction and that very rapid transamination provides for the equilibration of ${ }^{15} \mathrm{~N}$. (Ideally, an infusion of ${ }^{13} \mathrm{C}$-labeled isoleucine should have been used to circumvent this problem, but current commercial availability and cost of this material have prohibited such a study.) If transamination were extremely fast, not only would the isoleucine:alloisoleucine pools be in ${ }^{15} \mathrm{~N}$ equilibrium but so would the leucine pool. However, even after almost $6 \mathrm{hr}$ of infusion, leucine has a considerably higher ${ }^{15} \mathrm{~N}$ enrichment in both patients. Without a rapid rate of KMV enolization relative to the amino acid transamination rate, ${ }^{15} \mathrm{~N}$ enrichment in leucine would not be substantially higher than that of isoleucine and alloisoleucine whose ${ }^{15} \mathrm{~N}$ enrichments are identical.

Meister (10), studying the nonenzymatic enolization of KMV, noted that the rate of racemization of (+)- or (-)-KMV was proportional to the concentration of KMV. In our study, VMSUD had a lower plasma isoleucine concentration (6) than the C-MSUD patient and would be expected to have a lower KMV concentration (8) consistent with our finding that the V-MSUD subject had a lower alloisoleucine concentration relative to isoleucine than did the C-MSUD patient. This observation may account for the slower equilibration of $\left[{ }^{15} \mathrm{~N}\right]$ alloisoleucine with that of $\left[{ }^{15} \mathrm{~N}\right]$ isoleucine to this subject.

In conclusion, we have presented significant in vivo evidence in favor of the formation of alloisoleucine in MSUD via the ketoenol tautomerization mechanism shown in Figure 1.

\section{REFERENCES AND NOTES}

1. Adams, R. T.: Determination of amino acid profiles in biological samples by gas chromatography. J. Chromatogr., 95: 189 (1974).

2. Bier, D. M. Arnold, K. J., Sherman, W. R., Holland, W. H., Holmes, W. F., and Kipnis, D. M.: In vivo measurement of glucose and alanine metabolism with stable isotopic tracers. Diabetes, 26: 1005 (1977).

3. Dancis, $\mathbf{J}$, and Levitz, M.: Abnormalities of branched-chain amino acid metabolism. In: J. B. Stanbury, J. B. Wyngaarden, D. S. Fredrickson: The Metabolic Basis of Inherited Disease. 4th ed., pp. 39-40 (Blakiston, New York, N. Y., 1978).

4. Frank, H., Nicholson, G. J., and Bayer, E.: Rapid gas chromatographic separation of amino acid enantiomers with a novel chiral stationary phase. J. Chromatogr. Sci., 15: 174 (1977).

5. Halpern, B., and Pollock, G. E.: The configuration of the alloisoleucine present in maple syrup urine disease plasma. Biochem. Med., 4: 352 (1970).

6. Haymond, M. W., Ben-Galim, E., and Strobel, K. E.: Glucose and alanine metabolism in children with maple syrup urine disease. J. Clin. Invest., 62: 398 (1978).

7. Jakobs, C., Solem, E., Ek, J., Halvorsen, K., and Jellum, E.: Investigation of the metabolic pattern in maple syrup urine diseae by means of glass capillary gas chromatography and mass spectrometry. J. Chromatogr., 143: 31 (1977).

8. Langenbeck, U., Wendel, J., Mench-Hoinowski, A., Kuschel, D., Becker, K. Przyrembel, H., and Bremer, H. J.: Correlations between branched-chain amino acids and branched-chain $\alpha$-keto acids in maple syrup urine disease. Clin. Chim. Acta, 88: 283 (1978).

9. Matthews, D. E., Ben-Galim, E., and Bier, D. M.: Determination of stable isotopic enrichment in individual plasma amino acids by chemical ionization mass spectrometry. Anal. Chem., 51: 80 (1979).

10. Meister, A.: Studies on D- and L- $\alpha$-keto- $\beta$-methyl-valeric acids. J. Biol. Chem., 190: 269 (1951)

11. Norton, P. M., Roitman, E., Snyderman, S. E., and Holt, L. E.: A new finding in maple-syrup-urine disease. Lancet, $1: 26$ (1962).

12. Snyderman, S. E., Norton, P. M., Roitman, E., and Holt, L. E.: Maple syrup urine disease, with particular reference to dietotherapy. Pediatrics, 34: 454 (1964).

13. Taylor, R. T., and Jenkins, W. R.: Leucine aminotransferase. II. Purification and characterization. J. Biol. Chem., 241: 4396 (1966).

14. Westall, R. G., Dancis, J., and Miller, S.: Maple sugar urine disease. Am. J. Dis. Child., 94: 571 (1957).

15. Requests for reprints should be addressed to: Dr. D. E. Matthews, Washington University School of Medicine, Metabolism Division, 660 S. Euclid, St. Louis, MO 63110 (USA).

16. This research was supported by The National Foundation-March of Dimes and by National Institutes of Health grants HD-10667, AM-06355, and RR-00036.

17. Received for publication June 18, 1979.

18. Accepted for publication October 22, 1979. 